This item was submitted to Loughborough's Research Repository by the author.

Items in Figshare are protected by copyright, with all rights reserved, unless otherwise indicated.

\title{
Effect of microneedle type on transdermal permeation of rizatriptan
}

PLEASE CITE THE PUBLISHED VERSION

http://dx.doi.org/10.1208/s12249-016-0702-0

\section{PUBLISHER}

Springer (c) American Association of Pharmaceutical Scientists

\section{VERSION}

AM (Accepted Manuscript)

\section{PUBLISHER STATEMENT}

This work is made available according to the conditions of the Creative Commons Attribution-NonCommercialNoDerivatives 4.0 International (CC BY-NC-ND 4.0) licence. Full details of this licence are available at: https://creativecommons.org/licenses/by-nc-nd/4.0/

\section{LICENCE}

CC BY-NC-ND 4.0

\section{REPOSITORY RECORD}

Uppuluri, Chandrateja, Ashraf Sultana Shaik, Tao Han, Atul Nayak, Karthik J. Nair, Benjamin R. Whiteside, Buchi N. Nalluri, and Diganta Bhusan Das. 2017. "Effect of Microneedle Type on Transdermal Permeation of Rizatriptan”. figshare. https://hdl.handle.net/2134/24671. 


\section{EFFECT OF MICRONEEDLE TYPE ON TRANSDERMAL PERMEATION OF RIZATRIPTAN}

Chandra Teja U', Ashraf Sultana SK ${ }^{\mathrm{a}}$, Tao Han ${ }^{\mathrm{b}}$, Atul Nayak ${ }^{\mathrm{b}}$, Karthik J. Nairc, Benjamin R. Whitesidec ${ }^{c}$, Buchi N. Nalluri*a ${ }^{\text {, Diganta B. Das*b }}$

${ }^{a}$ Department of Pharmaceutics, KVSR Siddhartha College of Pharmaceutical Sciences, Vijayawada-520010, AP, India

${ }^{b}$ Department of Chemical Engineering, Loughborough University, Loughborough LE11 3TU, UK

${ }^{c}$ Department of Engineering and Informatics, University of Bradford, Bradford BD7 1DP, UK

* Corresponding Authors

Buchi N. Nalluri, Professor and Director for PG Studies and Research, KVSR Siddhartha College of Pharmaceutical Sciences, Vijayawada-520010, AP, India E-mail: buchinalluri@yahoo.com

Telephone: +91-9618394959

Diganta B. Das, Department of Chemical Engineering, Loughborough University, Leicestershire, LE11 3TU, UK E-mail:D.B.Das@lboro.ac.uk Telephone: +44-1509222509 


\section{ABSTRACT}

2 The present study was aimed to investigate the effect of salient microneedle (MN) geometry

3 parameters like length, density, shape and type on transdermal permeation of Rizatriptan

4 (RIZ). Studies were carried out using two types of MN devices viz. AdminPatch ${ }^{\circledR}$ arrays $5 \quad(\mathrm{ADM})(0.6,0.9,1.2$ and 1.5mm lengths), and laboratory fabricated polymeric MNs (PM) of $60.6 \mathrm{~mm}$ length. In the case of the PMs, arrays were applied three times at different places 7 within a $1.77 \mathrm{~cm}^{2}$ skin area (PM-3) to maintain the $\mathrm{MN}$ density closer to $0.6 \mathrm{~mm}$ ADM. 8 Histological studies revealed that PM, owing to their geometry/design, formed wider and 9 deeper microconduits when compared to ADM of similar length. Approximately 4.9 and 4.2 10 fold increase in the RIZ steady state flux values were observed with 1.5mm ADM and PM-3 applications when compared to the passive studies. A good correlation between different dimensionless parameters like the amount of RIZ permeated $\left(C_{t} / C_{s}\right)$, thickness $(h / L)$ and surface area $\left(\mathrm{Sa} / \mathrm{L}^{2}\right)$ of the skin was observed with scaling analyses. Numerical simulations provided further information regarding the distribution of RIZ in MN treated skin after application of different MNs. Overall, the study suggests that MN application enhances the RIZ transdermal permeation and the geometrical parameters of MNs plays an important role in the degree enhancement.

Keywords: Histological sections, Microneedles, Microneedle Geometry, Numerical simulations, Rizatriptan, Scaling analyses, Transdermal enhancement 
Transdermal drug delivery (TDD) offers many advantages over conventional oral or injection delivery methods, for example, avoidance of hepatic first pass metabolism, non-invasive nature of drug application and ability to deliver the drugs over a prolonged period of time, etc. All of these factors contribute to improved patient compliance and acceptability of drug therapy. TDD is gaining a lot of interest as a possible alternative route of administration for a wide array of therapeutic agents (1-3).

However, the greatest bottleneck with transdermal delivery is that only a limited number of drug molecules with a precise combination of physicochemical properties can permeate through skin at clinically relevant/effective levels. The protective function of the skin, especially the outermost layer comprising of dead skin cells, the stratum corneum (SC), which is only 10 to $50 \mu \mathrm{m}$ thick, imposes limitations on the drug molecules to permeate across skin and to reach the systemic circulation. However, with the advent of research in TDD, several techniques have been proposed to attenuate or bypass the barrier function of skin enabling the efficient delivery of drugs (3-6).

Migraine is a chronic, debilitating headache prevalent in about $19 \%$ of the global population with 2-3 times more incidence in women than in men (7). Rizatriptan, commonly available as its benzoate salt, (RIZ), an anti-migraine agent, is available as oral IR (immediate release) and ODT (oral disintegrating tablet) formulations, with an absolute bioavailability of about 45\%. Moreover, with these formulations, a good chance of therapeutic failure within $2 \mathrm{~h}$ after administering the first dose and recurrence of the attack within $24 \mathrm{~h}$ were reported $(8,9)$. Transdermal delivery may be seen as a good non-invasive alternative for RIZ administration with prolonged duration of action, increased bioavailability, reduced recurrence and increased 
ideal properties to permeate through the skin. Hence, a suitable permeation enhancement technique should be employed to achieve clinically significant rates of drug permeation. Microneedles (MN), a novel transdermal permeation enhancement technique, are minimally invasive and potentially painless method of overcoming the barrier properties of skin for enhanced delivery of drugs (6). This technique has many advantages when compared to hypodermic injection, is believed to make conduits of micrometer dimensions in skin layers in the epidermal layers (especially, SC) and thus believed to enhance the transdermal permeation of drugs (10). MNs are known to improve the permeation of drug molecules, including macromolecules like insulin, growth hormone, etc $(5,11-13)$. It has been reported in the literature that several geometric parameters of MNs like shape, dimensions, density of $\mathrm{MN}$ on the device and type etc. play important roles in enhancing the transdermal permeation of drugs (14). There is also interplay of the effect of these variables and, as such, their effects on the permeation of a drug molecule are generally non-intuitive. As a result, their effects are best studied for specific case.

Motivated by this idea, the present study was designed as a systematic approach to explore the effect of MN geometry on the extent of RIZ transdermal permeation enhancement. Two types of MN devices viz. commercially available AdminPatch $^{\circledR}$ arrays (ADM) $(0.6,0.9,1.2$ and $1.5 \mathrm{~mm}$ length) and laboratory fabricated polymeric MN arrays (PM) (0.6 mm length) of different MN densities were employed in this investigation (Fig 1). A number of different techniques like etching, lithography and moulding were discussed widely in the literature for the manufacture of MNs of different dimensions (100-1800 $\mu \mathrm{m}$ in length), shapes with different materials (plastics, silicon, ceramics, metals, etc.). Injection moulding offers several advantages in terms of ease of scalability for bulk manufacture, range of materials and good reproducibility (15). In this study, micro-injection moulding was employed for fabrication of 
the polymeric MN arrays (PM) using PEEK LT-3 (polyether ether ketone) as reported in previous paper (16).

Surface visualization and histological evaluation of skin samples were carried out to confirm and to study formation miroconduits by application of either types of MN devices. Moreover, the obtained RIZ permeation data was subjected to mathematical treatment using scaling analyses to obtain correlations between dimensionless parameters like amount of RIZ permeated $\left(C_{t} / C_{s}\right)$ and various variables of the study like surface area $\left(\mathrm{Sa} / \mathrm{L}^{2}\right)$ and thickness $(\mathrm{h} / \mathrm{L})$ of skin based on the principles of Buckingham $\pi$ theorem as described in a previous papers $(17,18)$. Furthermore, numerical simulations using passive diffusion coefficient values, based on histological section images, were carried out using MATLAB and COMSOL programmes in order to gain insights into the phenomenon of RIZ transport behaviour and distribution in the skin layers $(18,19)$.

\section{MATERIALS AND METHODS}

\section{Materials}

AdminPatch ${ }^{\circledR}$ MN arrays were purchased from AdminMed, Sunnyvale, U.S.A. Rizatriptan benzoate was obtained from Mylan Laboratories Limited, Hyderabad, India; Sodium chloride, isopropyl alcohol, propylene glycol and 1\%w/v Safranin solution from Loba Chemie, Mumbai, India; Formic acid, acetonitrile, methanol and HPLC water from Merck Specialities Pvt. Ltd, Mumbai, India; Haematoxylin and Eosin stain from Sigma-Aldrich, Bengaluru, India. All the reagents and chemicals used in the study were of HPLC grade. Pig ear skin was obtained from local abattoirs.

\section{Fabrication of Polymeric MN (PM)}

Moulding of the MNs was performed on a micro-power 15 micro-injection moulding machine as shown in Fig 2 A. It is the latest micromoulding machine from Battenfeld 
95 (Wellingborough, UK) and was employed for the fabrication of PM for its high repeatability, accurate dosing, clean room facility, etc., which is ideal for bulk manufacture of MNs. PEEK LT-3 (Polyetheretherketone) is an FDA approved semi-crystalline biomaterial manufactured by Invibio Inc, Lancashire, UK and is widely employed for medical use. The main feature of PEEK LT-3 include its excellent processability, dimensional stability and high mechanical performance and resilient to repeated gamma radiation and was hence selected for the fabrication of MN arrays (16). The MN mould insert (Fig 2 B) was made out of Stavax ESR (Bohler-Uddeholm Corp, Elgin, USA). Sink electrical discharge machining (EDM) was used to create negative $\mathrm{MN}$ features into the insert and was outsourced to Isometric tool and design Inc. (New Richmond, USA). The moulding parameters for PM were mentioned in the Table I.

\section{MN dimensional evaluation}

\section{Scanning electron microscope (SEM):}

A Hitachi TM-3000 table-top Scanning Electron Microscope was used for analysis of the MN insert and needle geometry. The Hitachi TM-300 has a magnification from 15X to 30000X, sample chamber of $700 \mathrm{~mm}$ diameter and $50 \mathrm{~mm}$ thickness. It features $5 \mathrm{kV}, 15 \mathrm{kV}$ and analysis observation modes. Because of the high aspect ratio and low contrast of the MNs, analysis mode was used for imaging. The major advantage of using TM 3000 SEM was it works under low vacuum and does not need specimen coating.

\section{Confocal laser microscope:}

It is very important to measure the tip radius and height of the MNs and the most common methods used are optical or electron microscopy. Because of its steep and complex structures, a 3D image analysis gives a better measurement of the needle geometry and quality control. 
In this study an Olympus vertical scanning laser confocal microscope LEXT OLS 4000 was used to accurately measure the tip radius and height of MN arrays.

The device offers a broad magnification range from $108 \mathrm{X}$ to $17280 \mathrm{X}$ and the exact $3 \mathrm{D}$ reconstruction of the MNs. The confocal laser microscope LEXT scans the surfaces with a laser beam with the wavelength of $405 \mathrm{~nm}$ thus allowing submicron visualization of material and component surfaces with the resolution of down to $0.10 \mu \mathrm{m}$. Measurements were taken with the 20X lens using the wide range stitching feature with 20 percent overlap to produce a measurement area of $5 \mathrm{~mm} \times 5 \mathrm{~mm}$. A five level brightness switch (Table II) was enabled to accurately illuminate the specimen.

\section{Analysis of samples}

RP-HPLC-PDA method was developed specifically for the analysis of RIZ in the transdermal permeation samples. A Shimadzu Prominence HPLC system provided with DGU-20A3 degasser, LC-20AD binary pumps, SIL-20AHT auto sampler and SPD-M20A PDA detector was used for analysis of the samples. Data acquisition was carried out using LC solutions software. Separation was achieved on an Agilent Eclipse column $(150 \times 4.6 \mathrm{~mm} ; 5 \mu \mathrm{m})$. The mobile phase comprised of $0.02 \% \mathrm{v} / \mathrm{v}$ formic acid:methanol 75:25 (v/v) at a flow rate of $1 \mathrm{~mL} / \mathrm{min}$ with an injection volume of $20 \mu \mathrm{L}$ and the eluents were monitored at $221 \mathrm{~nm}$. The developed method was validated as per ICH guidelines.

\section{Solubility studies}

The solubility of RIZ was studied in different vehicle combinations of propylene glycol (PG), polyethylene glycol-400 (PEG), and saline (S) at 70:30, 80:20 and 90:10\% v/v ratios. To each vehicle system, excess amount of RIZ was added and vortexed for 1 min in order to obtain a saturated solution and the solutions were equilibrated at $37^{\circ} \mathrm{C}$ in an orbital shaker for $24 \mathrm{~h}$. After equilibration, the samples were centrifuged at $3000 \mathrm{rpm}$ for $10 \mathrm{~min}$ and filtered 
through a nylon syringe filter $(0.45 \mu \mathrm{m})$ and all the samples were appropriately diluted and analysed by HPLC method.

\section{Skin Preparation}

Pig ears were collected from the local abattoirs immediately after animals were killed by electric current. The ears were transported to the laboratory in a cooling box without previous treatment. In the laboratory, the pig ears were washed carefully with distilled water and the hair was removed from the external part of pig ear using an electrical hair clipper. Carefully the full-thickness skin from the external part of the pig ear was separated from underlying cartilage using a scalpel and excess fat underlying the skin was removed to a thickness of $1.2 \mathrm{~mm}$ was employed for the in vitro transdermal permeation studies. Dermis side was wiped with isopropyl alcohol to remove the residual adhering fat. Processed skin samples were individually wrapped in plastic bags without air entrapment and stored in a deep freezer at $-20^{\circ} \mathrm{C}$ till further use.

\section{Application of MNs on skin samples}

Prior to the in vitro skin permeation experiments, the skin samples were allowed to brought to the room temperature and then skin surface was carefully washed with saline. Two types of MN devices viz, $\operatorname{ADM}(0.6,0.9,1.2$ and $1.5 \mathrm{~mm})$ and $\mathrm{PM}(0.6 \mathrm{~mm})$ were tried to poke the skin surface under thumb pressure. In the case of PM, both single (PM-1) and triple (PM-3) insertions at different places within a $1.77 \mathrm{~cm}^{2}$ skin area $(\mathrm{PM}-3)$ were made in order to maintain the MN density closer to ADM of $0.6 \mathrm{~mm}$ length as shown in Fig 1 . The MNs were periodically checked in between usage for potential damages of the needles under a stereomicroscope. 


\section{Surface visualization and histological examination of the skin samples}

169

To visually confirm the ability of disruption of skin layers by MNs, the arrays were pressed over the pig ear skin under thumb pressure and held for $1 \mathrm{~min}$. Then the skin was stained with safranin dye $(1 \% \mathrm{w} / \mathrm{v}$ in water) and wiped with isopropanol cotton swabs for the identification of the microconduits formed. In the case of the histological studies the skin section samples with and without $\mathrm{MN}$ treatments were prepared after staining with haematoxylin and eosin for visualization of skin layers and to display a clear indentation by MN penetration. The sections were observed under a microscope (Olympus; Noida, India). The width and depth of microconduits formed were also calculated in triplicate ( $\mathrm{n}=3$ skin samples for each MN) with the help of Toup View 3.2 Software (Irwin, U.S.A). For control, skin samples without MN treatment were also prepared.

\section{In Vitro Skin Permeation Studies}

The in vitro transdermal permeation studies were performed using a vertical type Franz diffusion cell apparatus fitted with a water circulation system, a water heater and an eight stage magnetic stirrer (Orchid Scientifics, Nasik, India). Franz diffusion cells with an effective diffusion area of $1.77 \mathrm{~cm}^{2}$ and a receptor volume of around $14 \mathrm{~mL}$ were used. Saline was used as the receptor fluid. Pig ear skin was mounted between the donor and receptor cells with SC facing towards the donor cell. The receptor medium was stirred for uniform drug distribution at a speed of $600 \mathrm{rpm}$ throughout the experiment. Care was taken to prevent the air bubbles entrapment underside of the skin (dermis) and receptor solution. The surface of the skin was maintained at $32^{\circ} \mathrm{C}$ using a circulating water bath. After equilibration, $500 \mu \mathrm{L}$ of donor solutions containing excess amount of RIZ were applied on to the skin. Samples (500 $\mu \mathrm{L})$ were withdrawn from the receptor fluid at six hour increments up 
199

200

201

to $48 \mathrm{hr}$ and replaced with the fresh saline to maintain a constant volume. All the samples were stored at $4^{\circ} \mathrm{C}$, until analyzed by HPLC.

The cumulative permeation profiles were plotted for cumulative amount of drug permeated $\left(\mathrm{nmoL} / \mathrm{cm}^{2}\right)$ as a function of time, for untreated and microneedle treated skin. The flux values and the respective lag times were obtained from the slope and the $\mathrm{X}$-intercept of the steady state portion of the cumulative permeation profiles. Apparent permeability and diffusion coefficient values were computed from Fick’s first law of diffusion:

$$
\frac{1}{A}\left(\frac{d M}{d t}\right)=J_{s}=K_{p} \Delta C
$$

$\boldsymbol{J}_{\boldsymbol{s}}$ is the steady-state flux (nmoL/cm²/hr), $\boldsymbol{M}$ is the cumulative amount of drug permeating the skin $\left(\mathrm{nmoL} / \mathrm{cm}^{2}\right), \boldsymbol{A}$ is the area of the skin $\left(1.77 \mathrm{~cm}^{2}\right), \boldsymbol{K}_{\boldsymbol{p}}$ is the apparent permeability coefficient $(\mathrm{cm} / \mathrm{hr})$, and $\Delta \boldsymbol{C}$ is the difference in concentrations of RIZ in the donor and receiver. Sink conditions were maintained in the receiver throughout the experiment and hence $\boldsymbol{\Delta C}$ was approximated to the drug concentration in the donor compartment.

Enhancement ratios were also computed to evaluate the relative efficiency of different MNs on the RIZ skin permeation enhancement. The enhancement ratios were calculated as follows:

$$
\text { Enhancement Ratio }=\frac{\text { Cumulative amount or Flux obtained after MN application }}{\text { Cumulative amount or Flux obtained from passive studies }}
$$

\section{RIZ content in skin}

After the completion of the permeation studies, skin samples were studied for drug disposition. The skin tissue exposed to the donor solution was cut with a scalpel and washed 

with filtered water and blotted with a paper towel in order to remove the adhered drug to the

215 surface. Then skin was minced with a scalpel, and placed in a pre-weighed vial. The drug 216 was extracted from the skin by equilibrating with $5 \mathrm{~mL}$ of acetonitrile at $32^{\circ} \mathrm{C}$ in an orbital 217 shaker. The solutions were then analyzed by HPLC to determine the RIZ content. 
221 Dimensionless correlations between the amount of RIZ permeated $\left(C_{t} / C_{s}\right)$ and other variables

222 like thickness $(\mathrm{h} / \mathrm{L})$ and surface area $\left(\mathrm{Sa} / \mathrm{L}^{2}\right)$ of skin were made in order to gain insights into 223 the overall phenomenon of RIZ transdermal permeation enhancement by MN application. 224 The scaling analyses were carried out based on the principles of Buckingham $\pi$ theorem where it is defined that the dimensionless concentration of a drug, which permeates through skin, can be defined in terms of key non-dimensional parameters (e.g., MN lengths) using the procedures described in previous papers $(17,18)$. Eq.1 describes the relationship of all the model parameters used for such analyses (Table III).

$$
\frac{C_{t}}{C_{s}}=K\left[\frac{S_{a} L^{4} K_{e}}{V_{d} h D}\right]^{n}
$$

Where, ' $K$ ' is a dimensionless constant and ' $n$ ' is an unknown power; $C_{t}$ and $C_{s}$ are the amount of drug permeated at a given time t $(48 \mathrm{~h})$ and the amount of drug loaded in the donor compartment for diffusion (surface concentration on skin); $S_{a}$ is the surface area of skin available for diffusion; $\mathrm{L}$ is the length of microneedles; $\mathrm{K}_{\mathrm{e}}$ and $\mathrm{V}_{\mathrm{d}}$ are the first order elimination constant and the volume of receptor fluid; ' $h$ ' is the thickness of skin and D is the diffusion coefficient of RIZ in skin.

Using Eq.1, the correlations between the dimensionless RIZ concentration $\left(\mathrm{C}_{t} / \mathrm{C}_{\mathrm{s}}\right)$ against different dimensionless parameters of study, $\mathrm{h} / \mathrm{L}$ and $\mathrm{S}_{\mathrm{a}} / \mathrm{L}^{2}$, have been established considering that all other variables remain unchanged.

\section{Numerical simulations of experimental studies}

A set of well-defined numerical simulations were carried out in order to gain insights into the specific effects of MN shape, dimensions, force of insertion of $\mathrm{MN}$, etc. on the overall permeation enhancement of RIZ, and also to obtain the information about RIZ distribution 
within the skin layers during permeation, which are otherwise difficult to obtain directly from the experimental data. The simulations were carried out using MATLAB (Math Works, MA, USA) and COMSOL Multiphysics (COMSOL Multiphysics Pvt. Ltd., Stockholm, Sweden) programmes. The MATLAB programme was use to process the histological sections images of skin treated with MNs and these processed images were further coupled with the experimental permeation parameter, e.g., passive diffusion coefficient and imported into COMSOL simulator software $(18,19)$.

\section{Statistical analysis of the data}

Results of the experimental data were subjected to statistical analysis by one way ANOVA (using Fischer's LSD post hoc test) using SYSTAT 13 software (Systat Software Inc., San Jose, USA). Results with $p$ value of less than 0.05 were considered to have statistically significant variance. Mean of replicate measurements $(n=3)$ with corresponding standard deviation (SD) was used to represent the data and to plot the graphs.

\section{RESULTS}

\section{Fabrication and characterization of PM}

Polymeric MN arrays (PM) were fabricated using (PEEK)-LT3 (polyether ether ketone) using micro-injection moulding technique, with $25 \mathrm{MN}$ on each array (MN density) and the array base thickness of $300 \mu \mathrm{m}$. The dimensions of PM, determined using a 3D confocal imaging (Fig 3 A) and scanning electron microscopy (SEM) (Fig 3 B), were found to be 556

$265 \pm 30 \mu \mathrm{m}$ in height with a tip radius of $32 \pm 8 \mu \mathrm{m}$, with a base thickness of $300 \mu \mathrm{m}$ and $\mathrm{MN}$ interspacing of approximately $1 \mathrm{~mm}$ at the base.

267 For better comparison and understanding of the difference in the shape/design between PM and $\mathrm{ADM}$ devices, 3D confocal images of $0.6 \mathrm{~mm} \mathrm{ADM}$ were given in Fig $3 \mathrm{C}$. Also the 
difference in base thickness among the devices can be clearly observed from the Fig 1 . The various geometry parameters of both types of MN devices were given in Table IV.

\section{Analytical Method}

A rapid and sensitive HPLC-PDA method was developed for the selective quantification of RIZ in transdermal permeation studies. Under the developed LC conditions, RIZ eluted at 2.5 min (Fig 4A) with good peak shape. Also, the specificity of the method to RIZ was demonstrated by the UV spectrum and the peak purity index curves (Fig 4B, C). The method was validated as per ICH guidelines and complied with all the requirements (Table V)

\section{Solubility Studies}

Solubility studies for RIZ were performed with a view to select appropriate donor vehicle for conducting in vitro skin permeation studies. PG:S and PEG:S combinations at 70:30, 80:20 and 90:10 \%v/v were studied for RIZ solubility. The solubility data obtained was shown in Fig 5.

\section{Surface visualization and histological examination of skin samples}

In order to visually confirm the ability of disruption of skin layers by MNs, the arrays were pressed over the pig ear skin under thumb pressure and held for 1 min and the skin samples were stained with safranin (1\%w/v). The digital photographs of MN treated skin were shown in Fig 6. Histological section images of skin treated with MNs were shown in Fig 7. From the images, the stratum corneum disruption and the formation of microconduits across skin layers was clearly evident. The average penetration depth (vertical) $(n=3)$ of the MNs was found to be $180.26 \pm 30.39,302.22 \pm 22.28,400.85 \pm 20.83,478.48 \pm 67.72$ and $338.20 \pm$ $22.66 \mu \mathrm{m}$ for $\operatorname{ADM}(0.6,0.9,1.2,1.5 \mathrm{~mm})$ and $\mathrm{PM}$, respectively. 
The comparative in vitro pig ear skin permeation profiles of RIZ without and with MN application were shown in Fig 8. Various RIZ permeation parameters viz. cumulative amount

297 permeated at the end of $48 \mathrm{~h}$, steady state flux, lag time, permeability and diffusion coefficients without and with microneedle treatment were given in Table VI.

\section{Scaling analyses}

Using scaling analyses, correlations were developed between the dimensionless parameters, namely, the amount of RIZ permeated $\left(\mathrm{C}_{\mathrm{t}} / \mathrm{C}_{\mathrm{s}}\right)$ and skin thickness $(\mathrm{h} / \mathrm{L})$ and surface area of skin $\left(\mathrm{S}_{\mathrm{a}} / \mathrm{L}^{2}\right)$ in order to derive a better understanding on the effect of specific geometry parameters of MN, like length (L), on overall permeation enhancement by MNs of same design (ADM) (Fig 9A, B respectively) (17, 18). Eqs. 2 and 3 describe such relationships among the considered parameters within the given range. These correlations were determined for given thickness and surface area of skin while the MN length varies $(0.6,0.9$, 1.2 and $1.5 \mathrm{~mm})$.

\section{(1)}

$$
\begin{aligned}
& \frac{C_{t}}{C_{s}}=4.864 \times 10^{-3}\left[\frac{h}{L}\right]^{-1.592} \quad \text { for } \quad 0.8 \leq \frac{h}{L} \leq 2 \text {--- (2) } \\
& \frac{C_{t}}{C_{s}}=0.224\left[\frac{S_{a}}{L^{2}}\right]^{-0.796} \text { for } \quad 78.5 \leq \frac{S_{a}}{L^{2}} \leq 491.5 \text {--- (3) }
\end{aligned}
$$

Good correlation was observed $\left(\mathrm{R}^{2}>0.85\right)$ between the dimensionless parameters of the study (Fig 9).

\section{Numerical simulations of experimental studies}


The numerical simulations were carried out using the procedures discussed in previous papers based on in vitro passive diffusion coefficient values, coupled with histological section images (of corresponding MNs) $(18,19)$. Different stages in processing the histological section images by MATLAB and COMSOL programmes for simulations were shown in Fig 10. The numerical simulations were able to provide information regarding the skin distribution of RIZ after applying the MNs at any time point and depth (Fig 10 D).

\section{DISCUSSION}

The shape (conical) and dimensions of the PM were found to be consistent and repeatable with good tip shape, confirming the complete filling of the PEEK into the MN insert cavity under the maintained processing conditions (Table I) and the technique used is reliable for the bulk manufacture of PMs. Moreover, compression tests of PM on a steel plate using Bose Electroforce 3100 instrument with a $225 \mathrm{~N}$ load cell and Wintest ${ }^{\circledR}$ software (Bose, MN, USA) revealed that the PMs were able to withstand compression forces of up to $8 \mathrm{~N}$. Plastic deformation of the PMs was observed at forces greater than $16 \mathrm{~N}$, with no tip breaking. (16).

A rapid and sensitive HPLC-PDA method was developed for the selective quantification of RIZ in transdermal permeation studies (Fig 4). The method complied with all the requirements of ICH guidelines (Table V) and was successfully employed for the quantitative estimation of RIZ in various samples throughout the study. The solubility of RIZ was in the order 70:30>80:20>90:10 \%v/v in both PG:S and PEG:S solvent systems. Overall, the solubility of RIZ was significantly higher in PG:S 70:30 \%v/v combination when compared to others $(p<0.05)$ (Fig 5). Hence, PG:S 70:30 \%v/v combination was further selected as the donor vehicle in permeation studies. 
Surface visualization of the MN treated skin samples showed clear distinctions in the number of the microconduits formed as per the length and density of MNs in ADM and PM devices

(Fig 6). Histological section images clearly showed skin layer disruption and the formation of microconduits (Fig 7). The average penetration depth (vertical) was about 25-35\% for ADM and 55-60\% for the PM MN lengths (Fig 7). Even though the length of the MNs differ in $\mathrm{ADM}$, the percentage of $\mathrm{MN}$ penetration is almost same, which is an indication of uniformity in thumb pressure under which MNs were applied at different times.

With the ADM devices, as the length of the MNs increased the penetration depth also increased. However, the microconduits were found to be wider and deeper with PM when compared to ADM of similar lengths i.e. $0.6 \mathrm{~mm}$. These differences in the efficiency of creating microconduits in skin layers between the two types of MN devices (ADM and PM) may be attributed to the differences in geometry parameters like shape, design and type of fabricating material. Regarding the shape/design, PM being conical (3D) in shape, the microconduits formed by PM were wider, while that with ADM looks merely like a cut on the skin (2D) as the arrays of ADM are low in thickness (2D) (Fig 3). Furthermore, owing to the sturdy and thick base (when compared to ADM) that supports the solid PM (Fig 1), the effective resistance (because of the viscoelastic nature) of the skin during application of arrays may be less for PM, while the ADM might have experienced greater resistance which is because of their thin base and array design (20), resulting in a relatively shallow penetration with similar MN lengths (0.6 and $0.9 \mathrm{~mm}$ ADM).

Significant enhancement in RIZ permeation was observed after MNs application onto the skin $(p<0.05)$ when compared to passive permeation studies (Fig 8). A 1.76, 1.91, 3.55 and 7.41 fold increase in the cumulative amount (48 h) of RIZ permeated was observed with 0.6 , 0.9, 1.2 and $1.5 \mathrm{~mm}$ ADM treatments, respectively, when compared to passive permeation 
amount. A similar trend was observed with other permeation parameters like permeability and diffusion coefficient values (Table VI). Significant reduction in the lag time was observed after application of $1.5 \mathrm{~mm}$ ADM when compared to that with passive and other ADM lengths $(p<0.05)$. However, there is no statistically significant difference between passive and $0.6 \mathrm{~mm}$ and 0.9 and 1.2mm ADM treatments in terms of lag time ( $p>0.05)$. The RIZ flux values were found to be in the order of $1.5 \mathrm{~mm}>1.2 \mathrm{~mm}>0.9 \mathrm{~mm}>0.6 \mathrm{~mm}>$ passive with ADM treatments. A 4.88 fold increase in RIZ flux was observed with the 1.5 $\mathrm{mm}$ when compared to passive studies. However, there is no statistically significant difference between 0.6 and $0.9 \mathrm{~mm}$ treatments $(p>0.05)$. It was observed that the enhancement of RIZ permeation was only marginal with the application of 0.6 and $0.9 \mathrm{~mm}$ ADM when compared to passive studies (Fig 8). This may be due to the fact that the skin disruption/penetration caused by 0.6 and $0.9 \mathrm{~mm}$ ADM was less as supported by histological section images (Fig 7). Moreover, the RIZ permeation was high with $1.5 \mathrm{~mm}$ ADM when compared to 0.6, 0.9 and $1.2 \mathrm{~mm}$ even though the density of MNs is low, which is may be because of longer needle lengths which intern resulted in deeper skin penetration. With the PM application, a 1.62 and 6.35 fold increase in the cumulative amount (48 h) of RIZ permeated was observed with PM-1 and PM-3 treatments, respectively, when compared to passive permeation amounts. The lag times were found to be significantly lower for PM-3 when compared to passive and PM-1 treatments $(p<0.05)$. The RIZ flux values were found to be in the order of PM-3 > PM-1 > passive treatments. A 4.52 and 1.49 fold increase in RIZ flux was observed with the PM-3 and PM-1, respectively, when compared to passive studies. A similar trend was observed with other permeation parameters like permeability and diffusion coefficient values (Table VI) with both the PM treatments. 
391 Even though, the skin penetration by PM device (with $0.6 \mathrm{~mm}$ array) was significantly greater when compared to 0.6 and $0.9 \mathrm{~mm}$ ADM, the overall permeation enhancement in terms of flux, cumulative amount permeated etc. achieved with PM-1 was found to be closer to those of 0.6 and $0.9 \mathrm{~mm}$ ADM ( $p>0.05)$. This may be because the needle density of 0.6 and $0.9 \mathrm{~mm}$ ADM was greater when compared to PM-1 (Table III), which may have compensated the variation in the extent of skin penetration among these MNs, and thus no significant variation in overall permeation enhancement was observed among these three MNs ( $p>0.05)$. In case of the PM, a single application of array didn't cover the $1.77 \mathrm{~cm}^{2}$ surface area of the skin and hence in order to maintain the MN density closer to ADM of $0.6 \mathrm{~mm}$ length the arrays were applied three times at different places within a $1.77 \mathrm{~cm}^{2}$ skin area $(\mathrm{PM}-3)$ as shown in Fig 1. As the needle density was increased with PM-3, the RIZ transdermal permeation increased markedly and was similar to that obtained with $1.5 \mathrm{~mm}$ ADM ( $p>0.05)$. Moreover, it is intriguing to note although the needle density PM-3 (75 MNs) was significantly greater when compared to $1.5 \mathrm{~mm}$ ADM (31 MNs) the overall RIZ permeation enhancement was considerably greater with $1.5 \mathrm{~mm}$ ADM with significantly shorter lag times $(p<0.05)$, which may be because of deeper (vertical) penetration into skin. Even though the depth of the penetration was significantly lower with PM when compared to $1.5 \mathrm{~mm}$ ADM, the comparable permeation enhancement by PM-3 is may be because of higher needle density as stated earlier and wider microconduits formed as evidenced by histological section images (Fig 7)

The enhancement in RIZ permeation was found to be in the order of $1.5 \mathrm{~mm}$ ADM $\geq \mathrm{PM}-3>$ $1.2 \mathrm{~mm} \mathrm{ADM}>0.9 \mathrm{~mm} \mathrm{ADM} \geq 0.6 \mathrm{~mm} \mathrm{ADM} \geq \mathrm{PM}-1>$ Passive. Even though, no correlation of RIZ skin content was observed with different MN treatments, significantly higher amounts of RIZ were found to be distributed in skin layers at the end of $48 \mathrm{~h}$ with MN treated studies and is an indication of potential RIZ skin deposition. 
Overall, the transdermal permeation enhancement of RIZ by MN application is a complex

417 phenomenon and the permeation enhancement is dependent on the several aspects of the MN geometry like the shape/design, length and density etc.

419

420 Dimensionless correlations were developed for ADM MNs (same type but differing in 421 length) using scaling analyses. Good correlations were observed between the dimensionless parameters $\left(C_{t} / C_{s}\right.$ vs $h / L$ and $C_{t} / C_{s}$ vs $\left.S_{d} / L^{2}\right)$ (Fig 9). These correlations can be used to predict the amount of RIZ permeated $\left(C_{t} / C_{s}\right)$ with high accuracy for other MN lengths in the range of 0.6-1.5 mm with similar design as ADM. From the results of numerical simulations, the flux was represented by white arrows in the figures (Fig 10 D) showing obvious increment at the upper layers of the skin which is caused by $\mathrm{MN}$ penetration. This increment may be extrapolated to a higher drug accumulation rate at the blood stream as well as shorter lag time for the diffusion to reach its steady state after the application of MNs. Based on the simulation results, the diffusion profile of RIZ showed significant permeation increment with $1.5 \mathrm{~mm}$ ADM and PM when compared to other MNs in the study. Furthermore, the advantage of greater penetration by PM can be further magnified by increasing the MN density, as in the case of PM-3.

These simulations can be of great research value as they may be used to predict the degree of transdermal permeation enhancement of RIZ with other (new) dimensions and designs of MNs using the respective histological section images and the passive diffusion coefficient data.

\section{CONCLUSION}

439 Two types of MN devices (ADM and PM) were employed in this investigation to derive a 440 greater understanding on the effects of various geometry parameters specifically on the 
transdermal permeation of RIZ by MN application. It was observed that the application of MNs significantly enhance the transdermal permeation of RIZ across pig ear skin. Moreover, the type/shape, density and more importantly, the length of MNs (depth of penetration into skin) were found to play a crucial role in the overall permeation enhancement of RIZ using this technique. It may be inferred that the transdermal delivery of RIZ, at clinically significant levels and in a painless and non-invasive manner, may by possible using MN application. This investigation can form the basis for further studies (in vivo) and for optimization of various MN parameters to achieve successful delivery of RIZ via. MN assisted transdermal delivery systems.

\section{DECLARATION OF INTEREST}

The authors declare that there is no conflict of interest.

\section{ACKNOWLEDGEMENTS}

The authors are thankful to Mylan Pharmaceuticals India Ltd, Hyderabad, for providing a gift sample of RIZ, to Dr. Naveen, Department of Pathology, Dr. Pinnamaneni Siddhartha Institute of Medical Sciences and Research Foundation, Vijayawada, for providing the required facilities for taking histological sections of skin samples and also to the Siddhartha Academy of General and Technical Education, Vijayawada, for providing necessary facilities to carry out the research work. The authors also extend their sincere thanks to DST, Ministry of Science and Technology, Govt. of India and the British Council, London, UK, for funding this research work under the DST-UKIERI scheme (DST/INT/UK/P-60/2014). 
1. Brown MB, Gary PM, Stuart AJ, Franklin KA. Dermal and transdermal drug delivery systems: current and future prospects. Drug Delivery. 2006; 13: 175-187.

2. Prausnitz MR, Robert L. Transdermal drug delivery. Nat Biotechnol. 2008; 26: 1261-1268.

3. Cheung K, Das DB. Microneedles for drug delivery: trends and progress. Drug Deliv. 2015. DOI:10.3109/10717544.2014.986309 (in press).

4. Prausnitz MR, Samir M, Robert L. Current status and future potential of transdermal drug delivery, Nature Reviews Drug Discovery. 2004; 3: 115-124.

5. Ritesh K, Anil P. Modified transdermal technologies: breaking the barriers of drug permeation via the skin. Tropical Journal of Pharmaceutical Research. 2007; 6 (1): 633-644.

6. Han T, Das DB. Potential of combined ultrasound and microneedles for enhanced transdermal drug permeation: A review. Eur. J. Pharm. Biopharm. 2015; 89: 312328.

7. Silberstein SD. Migraine symptoms: results of a survey of self-reported migraineurs. Headache. 1995; 35(7): 387-96.

8. Rapoport AM, Tepper SJ, Sheftell FD, Kung E, Bigal ME. Which triptan for which patient? Neurol. Sci. 2006; 27: S123-S129.

9. Marcelo EB, Carlos AB, Ana LA, José G. The triptan formulations - a critical evaluation. Speciali Arq Neuropsiquiatr. 2003; 61(2-A): 313-320.

10. Gill HS, Denson DD, Burris BA, Prausnitz MR. Effect of microneedle design on pain in human volunteers. Clin. J. Pain. 2008; 24: 585-594.

11. Jeong W, Lee A, Jung-Hwan PB, Prausnitz MR. Dissolving microneedles for transdermal drug delivery Biomaterials. 2008; 29: 2113-2124. 
12. Zhou CP, Liu YL, Wang HL, Zhang PX, Zhang JL. Transdermal delivery of insulin using microneedle rollers in vivo. International Journal of Pharmaceutics. 2010; 39(2): 127-133.

492

13. Nalluri BN, Sai Sri Anusha $V_{2}$ Bramhini SR, Amulya J, Sultana AS,_Teja UC, Das DB. In vitro skin permeation enhancement of sumatriptan by microneedle application. Curr Drug Deliv. 2015; 12(6): 761-769.

14. Gomaa YA, Morrow DI, Garland MJ, Donnelly RF, El-Khordagui LK, Meidan 496 VM. Effects of microneedle length, density, insertion time and multiple applications on human skin barrier function: assessments by transepidermal water loss. Toxicol. In Vitro. 2010; 24(7): 1971-1978.

15. Attia UM, Marsona S, Alcock JR. Micro-injection moulding of polymer microfluidic devices. Microfluidics and nano fluidics. 2009; 7: 1-28.

16. Nair KJ, Whiteside BR, Grant C, Patel R, Tuinea-Bobe C, Norris K, Paradkar AR. Investigation of Plasma Treatment on Micro-Injection Moulded Microneedle for Drug Delivery, Pharmaceutics. 2015; 7: 471-485.

17. Al-Qallaf B, Das DB, Mori D, Cui Z. Modelling transdermal delivery of high molecular weight drugs from microneedle systems. Phil. Trans. R. Soc. A. 2007; 365: 2951-67.

18. Leeladurga V, Teja UC, Ashraf SS, Sundeep K, Sai Sri Anusha V, Han T, Nalluri BN, Das DB. Application of microneedle arrays for enhancement of transdermal permeation of Insulin: in vitro experiments, scaling analyses and numerical simulations. AAPS Pharma Sci Tech. 2015; 1-8. (DOI: 10.1208/S12249-015-04168). 

drug delivery aided by histology of microneedle-pierced skin. J. Pharm. Sci. 2015; 104(6): 1993-2007. Trademark Office. 
Table I. Microinjection moulding parameters

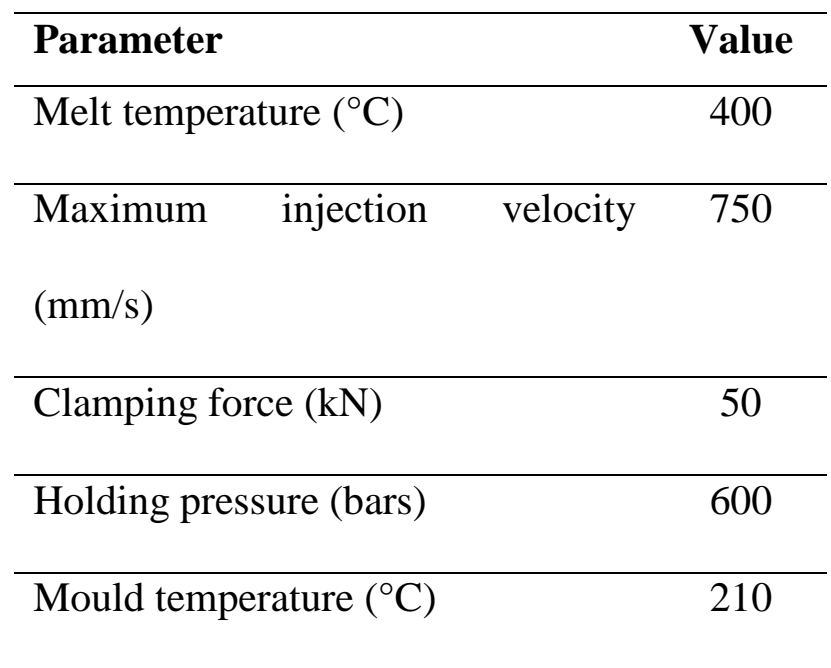


Table II. Brightness switch settings used for the confocal measurements

\begin{tabular}{cc}
\hline Position( $\boldsymbol{\mu m})$ & Brightness \\
\hline $\mathbf{6 0 0}$ & 49 \\
\hline $\mathbf{5 5 0}$ & 47.1 \\
\hline $\mathbf{5 2 0}$ & 49.1 \\
\hline $\mathbf{2 0}$ & 75.5 \\
\hline $\mathbf{0}$ & 48.4 \\
\hline
\end{tabular}

523

524

525 
Table III. Model parameters for dimensional scaling analyses of the data

\begin{tabular}{cc}
\hline Parameter & Value \\
\hline Duration for medication: $\mathrm{t}_{\mathrm{m}}$ & $48 \mathrm{~h}$ \\
\hline Surface area of skin exposed: $\mathrm{S}_{\mathrm{a}}$ & $1.77 \mathrm{~cm}^{2}$ \\
\hline Thickness of stratum corneum: $\mathrm{h}_{\mathrm{sc}}$ & $0.002 \mathrm{~cm}$ \\
\hline Total Thickness of membrane (distance & $0.12 \mathrm{~cm}$ \\
to blood vessel): $\mathrm{h}$ & Variable \\
\hline Effective skin thickness: $\mathrm{h}_{\mathrm{e}}$ & Variable \\
\hline Diffusion coefficient in viable skin: $\mathrm{D}$ & 14 mL \\
\hline Volume of Fluid in Receptor & \\
\hline Compartment (distribution): $\mathrm{V}_{\mathrm{d}}$ & as the donor solution \\
\hline Skin surface/Donor concentration: $\mathrm{C}_{\mathrm{s}}$ & Saturated Solution was charged \\
\hline Microneedle length: $\mathrm{L}$ & $0.09,0.12$ and $0.15 \mathrm{~cm}$ \\
\hline
\end{tabular}


Table IV. Different geometry parameters of MNs used in the study

\begin{tabular}{|c|c|c|c|c|c|}
\hline \multirow{2}{*}{ Parameter } & \multicolumn{4}{|c|}{ ADM* } & \multirow[t]{2}{*}{ PM } \\
\hline & 0.6 & 0.9 & 1.2 & 1.5 & \\
\hline Length $(\mu \mathrm{m})$ & 600 & 900 & 1200 & 1500 & $560 \pm 30$ \\
\hline Number of MNs $\left(1.77 \mathrm{~cm}^{2}\right)$ & 187 & 85 & 41 & 31 & 25 \\
\hline Shape & \multicolumn{4}{|c|}{ Flat (2D) } & Conical (3D) \\
\hline Thickness of each MN $(\mu \mathrm{m})$ & \multicolumn{4}{|c|}{78 (uniform till tip)** } & 300 ( 30 at tip) \\
\hline Thickness of array base $(\mu \mathrm{m})$ & \multicolumn{4}{|c|}{$100-200 * *$} & 300 \\
\hline Material & $\mathrm{Me}$ & dical & $\begin{array}{l}\text { rade st } \\
\text { SS } 316\end{array}$ & ss steel & $\begin{array}{c}\text { PEEK LT-3 (polyether } \\
\text { ether ketone) }\end{array}$ \\
\hline $\begin{array}{l}{ }^{*} \text { values are from } \\
* * \text { the width and }\end{array}$ & dis & $\begin{array}{l}\text { actur } \\
\text { ss of }\end{array}$ & $\begin{array}{l}(20) \\
\text { he } \mathrm{MN}\end{array}$ & $\mathrm{b}$ & es with length \\
\hline
\end{tabular}




\begin{tabular}{|c|c|}
\hline Linearity $(n=3)$ & \\
\hline Range & $0.2-3 \mu \mathrm{g} / \mathrm{mL}$ \\
\hline Regression equation & $y=78500 x-418.87$ \\
\hline Correlation coefficient & $\mathrm{R}=0.999$ \\
\hline Regression coefficient & $\mathrm{R}^{2}=0.999$ \\
\hline \multirow{2}{*}{ Precision $(n=6)$} & Average peak area of the standard sample (\%RSD) \\
\hline & $76214(0.529)$ \\
\hline \multicolumn{2}{|l|}{ Accuracy $(n=3)$} \\
\hline \multicolumn{2}{|r|}{ Mean Percent Recovery (\%RSD) } \\
\hline 80 & $100.31(0.685)$ \\
\hline 100 & $100.46(0.34)$ \\
\hline 120 & $100.08(0.980)$ \\
\hline
\end{tabular}

535

536 


\begin{tabular}{|c|c|c|c|c|c|c|}
\hline \multirow[b]{2}{*}{$\begin{array}{c}\text { Skin } \\
\text { treatment }\end{array}$} & \multicolumn{6}{|c|}{ Permeation Parameters } \\
\hline & $\begin{array}{l}\text { cumulative amount } \\
\text { permeated at } 48 \mathrm{~h} \\
\left(\mathrm{nmoL} / \mathrm{cm}^{2}\right)\end{array}$ & $\begin{array}{c}\begin{array}{c}\text { steady state } \\
\text { flux } \\
\left(\mathrm{nmoL} / \mathrm{cm}^{2} / \mathrm{h}\right)\end{array} \\
\end{array}$ & Lag Time (h) & $\begin{array}{c}\text { Permeability } \\
\text { coefficient } \\
\left({\left.\mathrm{x} 10^{-05}\right)}^{2}\right. \\
(\mathrm{cm} / \mathrm{hr}) \\
\end{array}$ & $\begin{array}{c}\text { Diffusion } \\
\text { coefficient } \\
\left(\mathrm{x} 10^{-08}\right) \\
\left(\mathrm{cm}^{2} / \mathrm{sec}\right) \\
\end{array}$ & $\begin{array}{l}\text { Skin Content } \\
(\mu \mathrm{g} / \mathrm{g})\end{array}$ \\
\hline Passive & $373.451 \pm 77.524$ & $12.648 \pm 1.212$ & $19.69 \pm 4.73$ & $2.271 \pm 0.218$ & $7.570 \pm 0.726$ & $794.30 \pm 174.43$ \\
\hline 0.6 ADM & $621.665 \pm 46.356$ & $18.664 \pm 0.84$ & $14.84 \pm 1.96$ & $3.348 \pm 0.152$ & $11.161 \pm 0.507$ & $1213.78 \pm 361.77$ \\
\hline 0.9 ADM & $715.246 \pm 89.447$ & $18.675 \pm 2.825$ & $9.98 \pm 0.91$ & $3.353 \pm 0.507$ & $11.178 \pm 1.691$ & $1200.94 \pm 260.13$ \\
\hline $1.2 \mathrm{ADM}$ & $1328.277 \pm 111.659$ & $33.435 \pm 3.182$ & $9.87 \pm 1.38$ & $6.004 \pm 0.571$ & $20.012 \pm 1.905$ & $1015.54 \pm 148.37$ \\
\hline $1.5 \mathrm{ADM}$ & $2767.532 \pm 209.109$ & $61.756 \pm 4.260$ & $4.17 \pm 0.85$ & $11.089 \pm 0.756$ & $36.963 \pm 2.550$ & $1566.92 \pm 628.71$ \\
\hline PM-1 & $602.023 \pm 17.269$ & $18.858 \pm 1.35$ & $16.31 \pm 2.05$ & $3.387 \pm 0.243$ & $11.29 \pm 0.809$ & $1247.31 \pm 445.51$ \\
\hline PM-3 & $2358.39 \pm 314.393$ & $57.199 \pm 9.03$ & $7.06 \pm 1.61$ & $10.273 \pm 1.62$ & $34.243 \pm 5.406$ & $1338.26 \pm 345.97$ \\
\hline
\end{tabular}


540 FIGURES

541
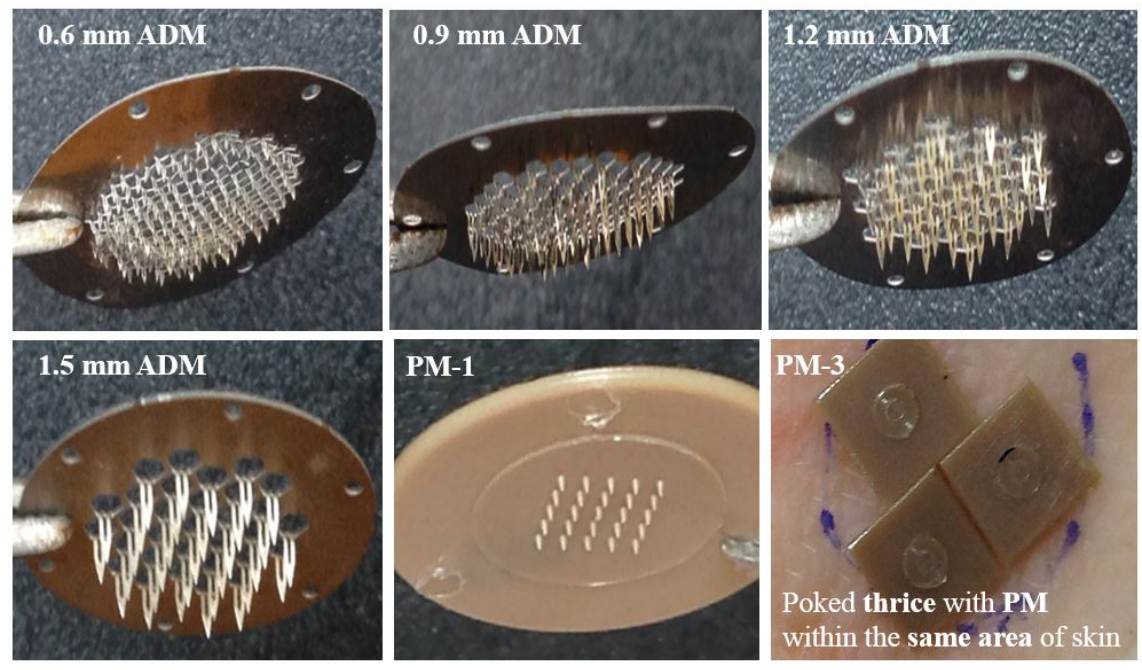

Fig 1

543 

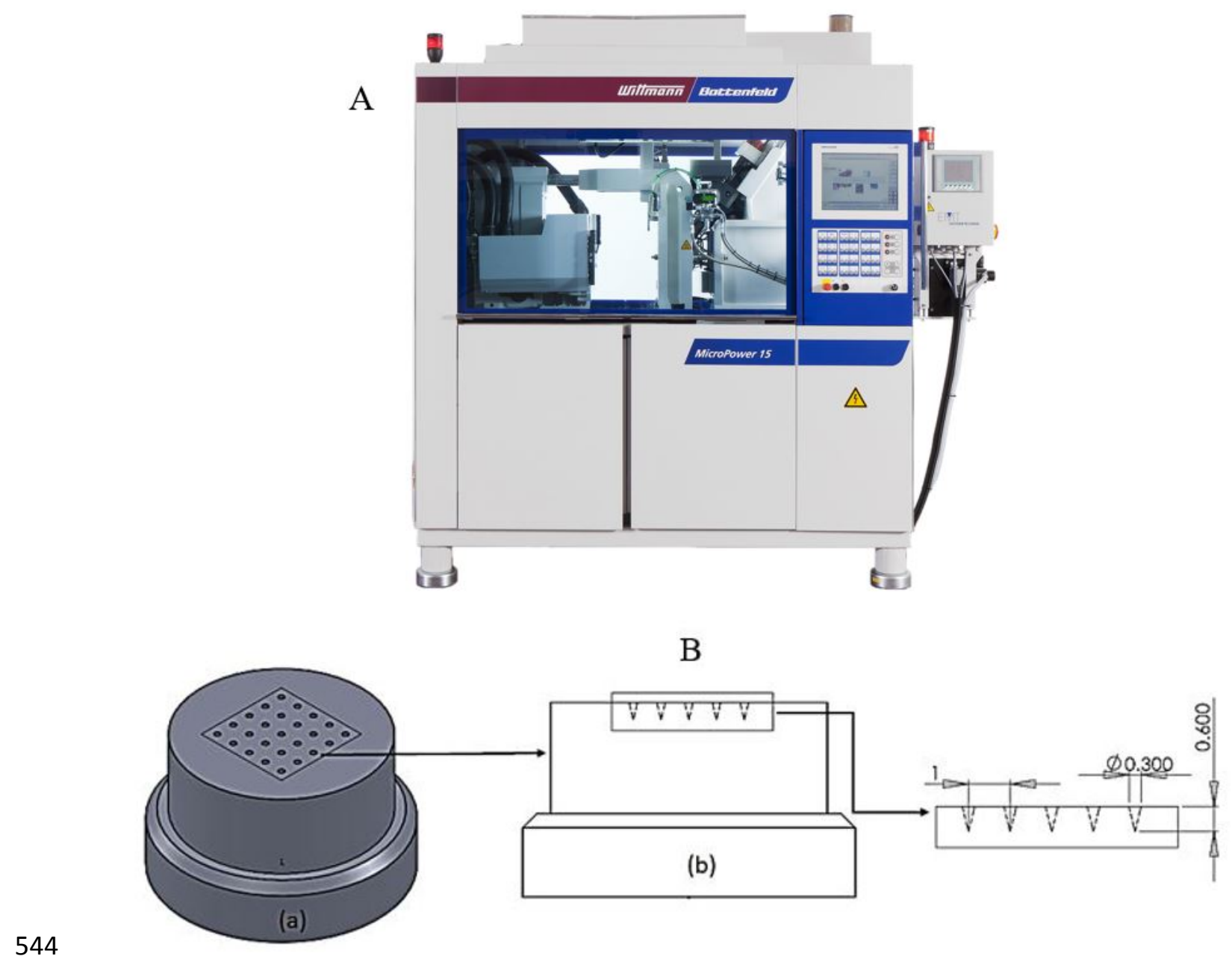

545

Fig 2

547 


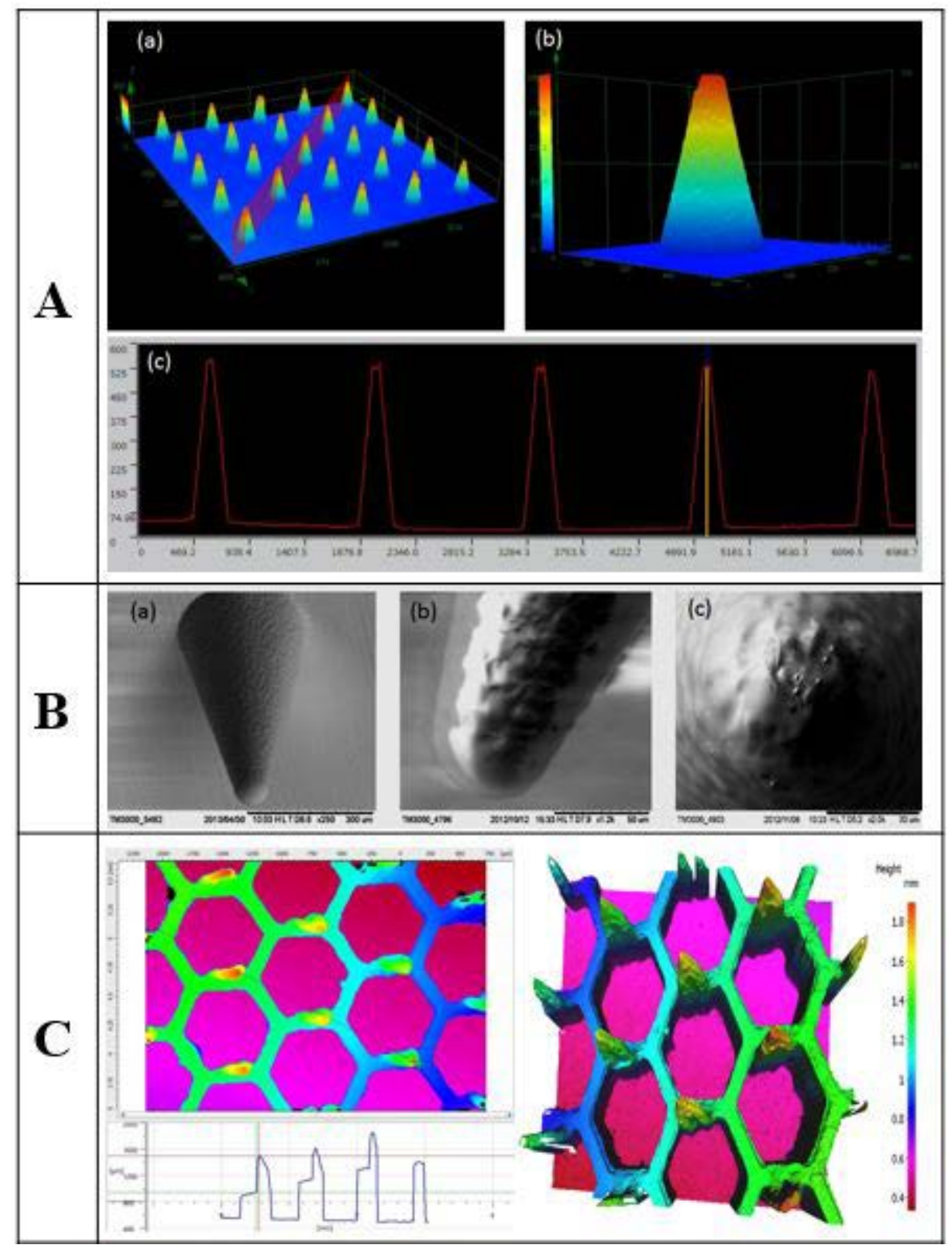

Fig 3 


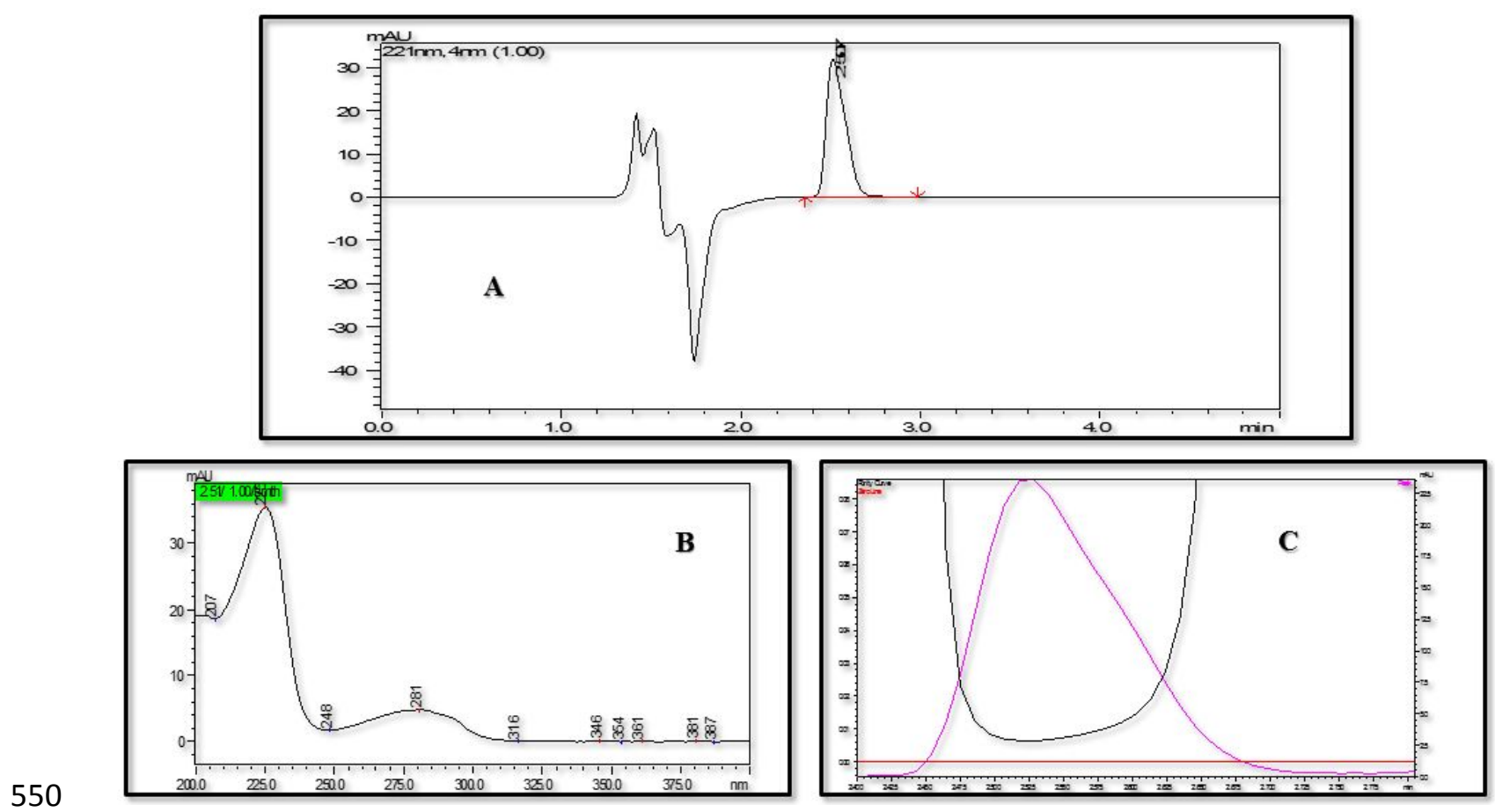

551

Fig 4

552 


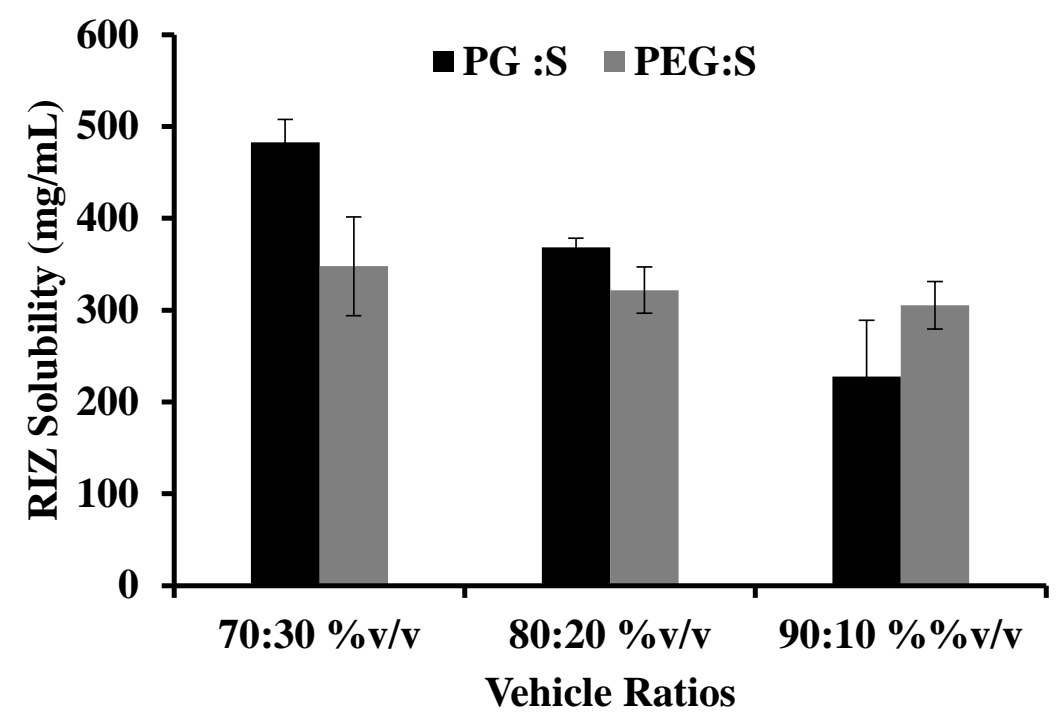

553

554

Fig 5

555 

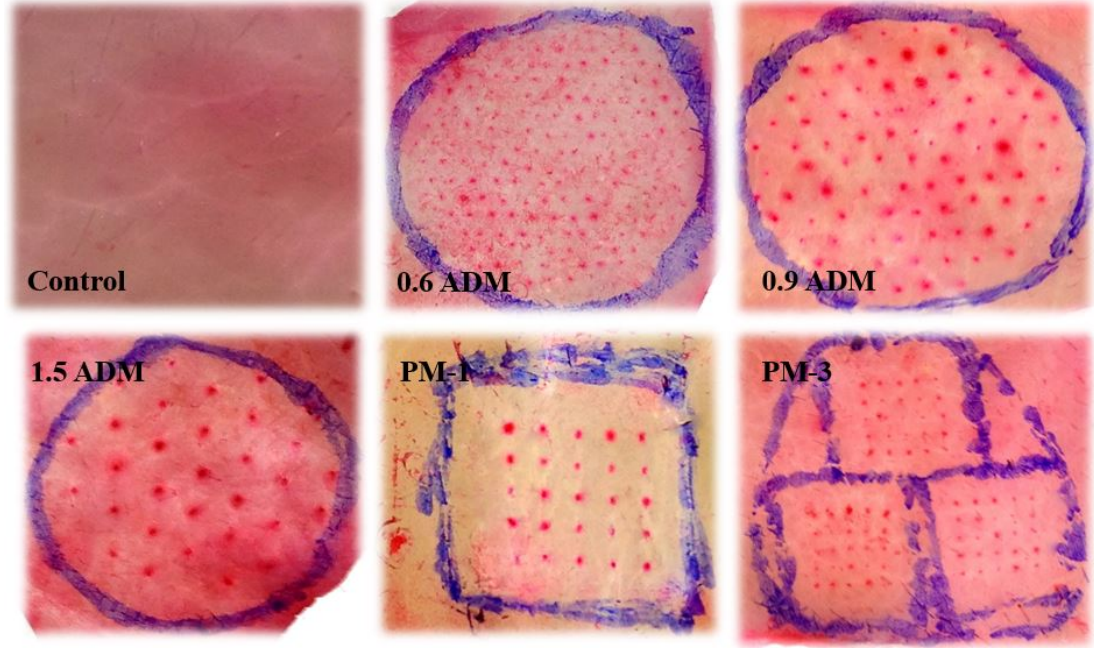

557

Fig 6

558 

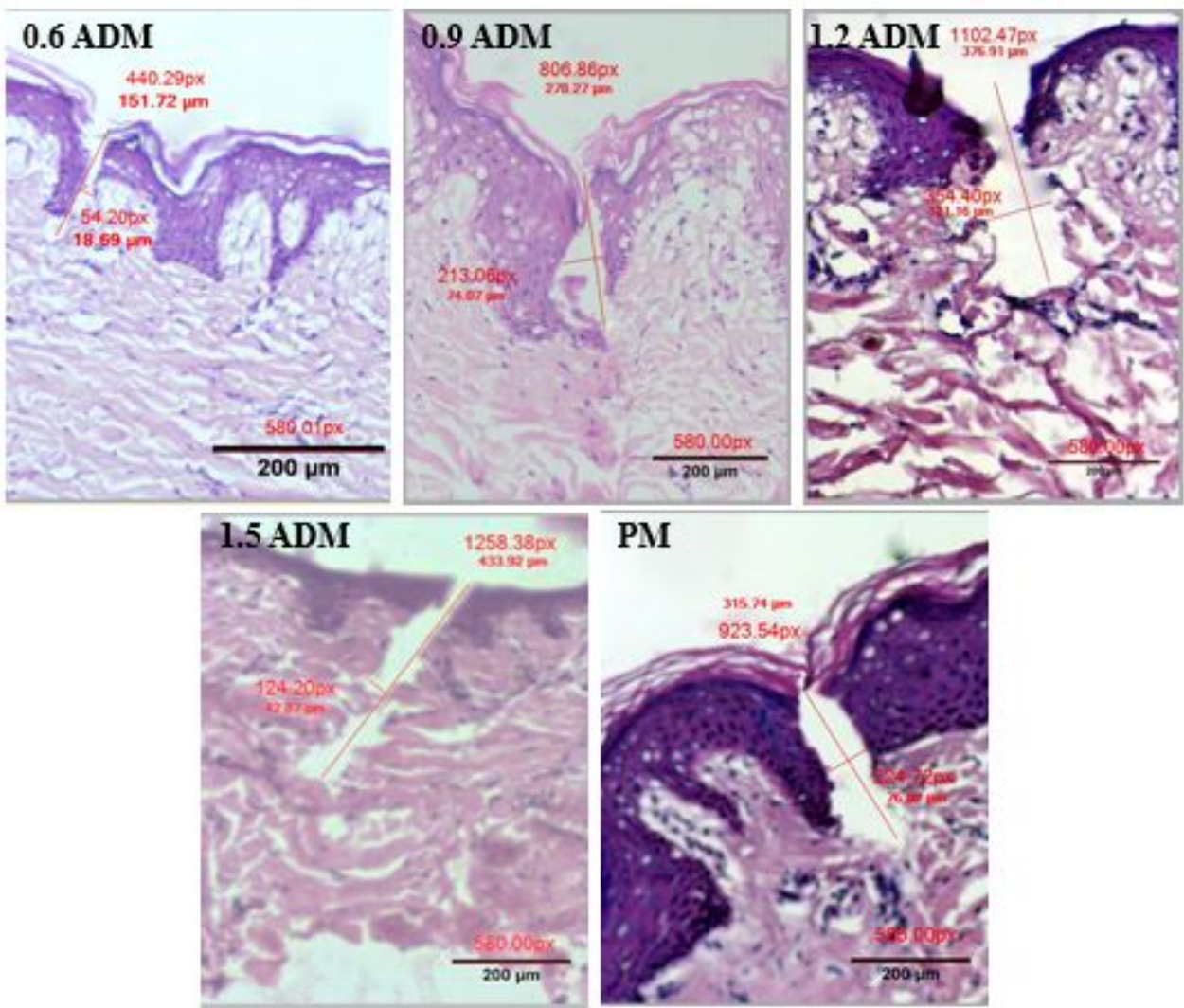

Fig 7

561 


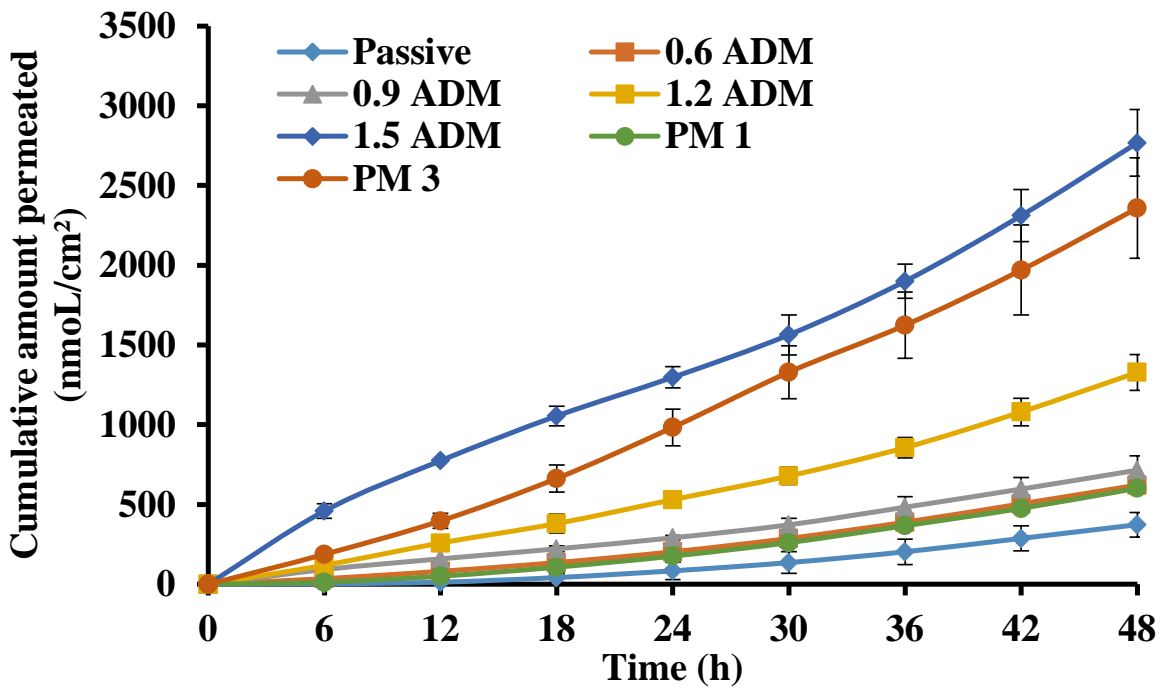

Fig 8 

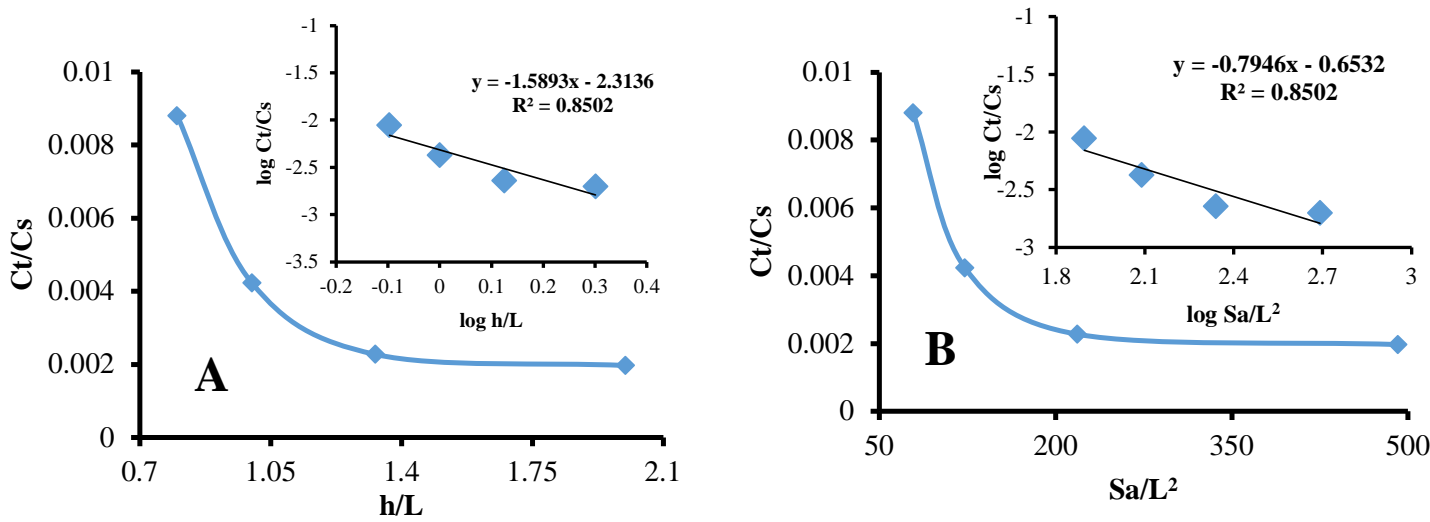

Fig 9 


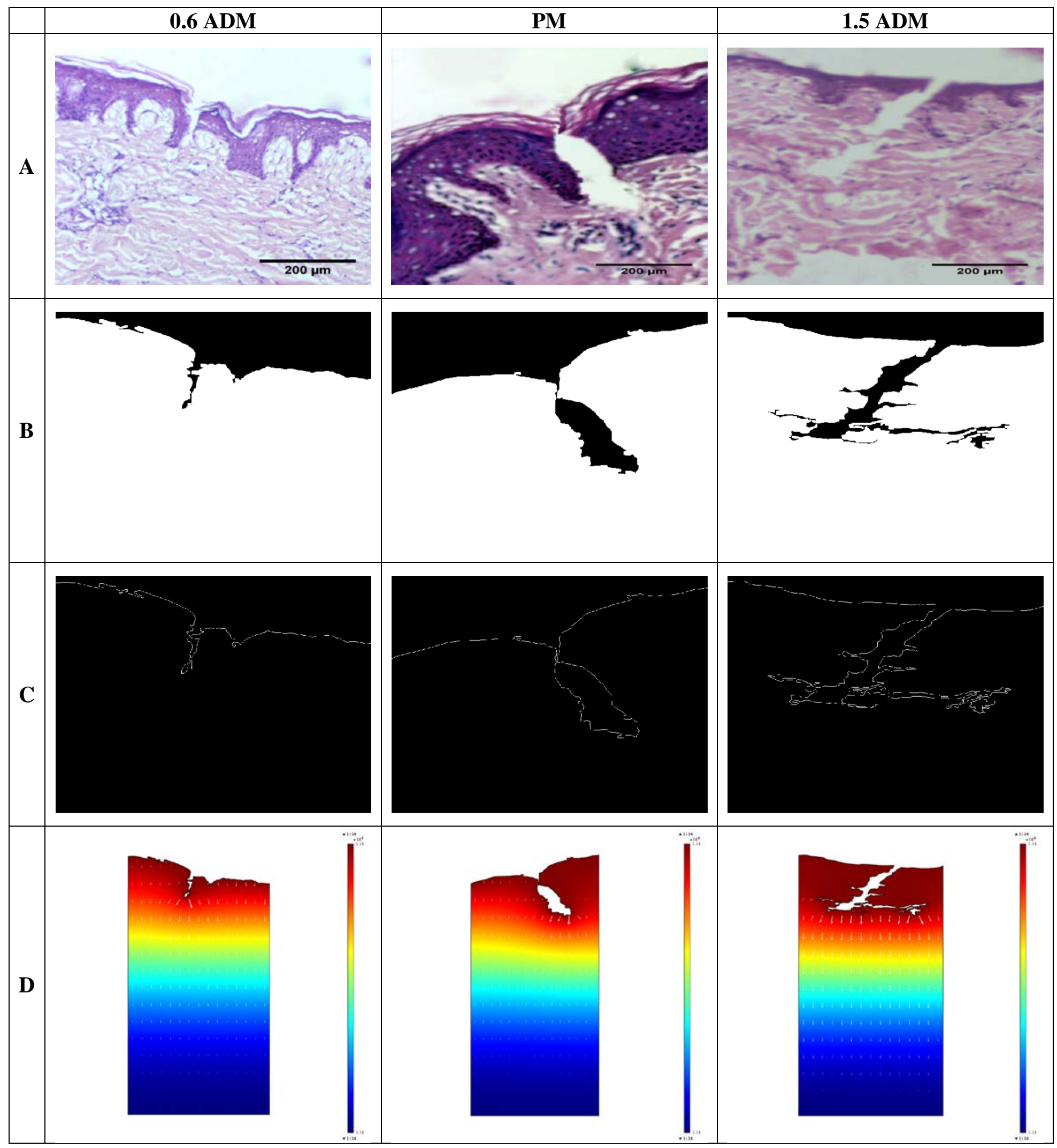

569

570

Fig 10

571 


\section{LEGENDS TO FIGURES}

573 Fig 1. Different MNs used in the study

574 Fig 2. (A) Battenfeld micro-power 15 moulding machine; (B) (a) 3D drawing of the

575 microneedle insert (b) dimensions of the insert created using Solid-works CAD software 576 (dimensions are in $\mathrm{mm}$ )

577 Fig 3. (A) $3 \mathrm{D}$ confocal image of (a) front view of the PEEK MN array (b) Single MN of 578 PEEK (c) line measurement of the needle array; (B) SEM image of the PEEK MNs (a) single 579 needle 250X (b) single needle 1200x (c) single needle 2000x; (C) Representative 3D confocal 580 image of 0.6 ADM showing its design parameters

581 Fig 4. RIZ Chromatogram (A); UV Spectrum (B); Peak Purity Index (C)

582 Fig 5. Solubility Data of RIZ in PG:S and PEG:S Solvent Systems

583 Fig 6. Surface images of stained skin without and with MN treatment

584 Fig 7. Typical histological section which were used for MN penetration depth calculation of $585 \quad$ ADM and PM in skin (ToupView ${ }^{\circledR}$ screenshot)

586 Fig 8. Comparative in vitro skin permeation profiles of RIZ from passive and MN treatments

587 Fig 9. Scaling relationship of different dimensionless groups for permeation of RIZ- (A) 588 Effects of dimensionless length of microneedles; (B) Effects of dimensionless surface area 589 for diffusion

590 Fig 10. A - The histological section images of skin. B, C - Images treated and processed with 591 MATLAB program. D - Drug distribution using images simulated in COMSOL 